\title{
Improving Student Interest in Engineering Curricula - Exciting Students about their Classes
}

\author{
Adeel Khalid \\ Systems and Mechanical Engineering Department, Southern Polytechnic State University \\ *Corresponding Author: akhalid2@spsu.edu
}

Copyright (C) 2013 Horizon Research Publishing All rights reserved.

\begin{abstract}
In this paper, we explore what events, activities, and teaching styles invoke student interest in engineering courses. The research is based on inputs from some of the best and award winning faculty members across disciplines. The activities that professors use to keep students engaged are highlighted. Similarly, the actions that professors take to turn students away are discussed.
\end{abstract}

Keywords Engaged Learning, Engineering Curricula, Motivating Students

\section{Introduction}

As engineering educators, it is not hard to observe that often students take a lot more interest in certain engineering courses than others. There are courses that students wait to enroll in, the classes fill up quickly and there is often a waiting list. Most of the class sessions are well attended. Students often stay back after the classes and pursue the professor to proactively learn the material. Student performance in these classes is often reflected in their grades. On the other hand, there are classes in which students enroll only because those classes are required for the degree they are pursuing. Those classes usually do not fill up, students often skip sessions, and the poor performance is reflected in the grades. In this study, the author explores what makes some classes so appealing while the others are perceived as dull and tedious. The research is based on feedback received from some of the best professors in various disciplines. It is observed that professors who go an extra mile can make just about any class interesting. An engineering class can be made interesting and enjoyable by engaging students in activities beyond those required in a typical class. These engaging activities include but are not limited to inviting guest speakers, taking students on field trips, showing related documentaries, involving students in laboratory work, involving students in research projects, having students develop laboratory apparatus and involving them in writing grants and research papers. By using these and other activities, professors not only earn respect in the eyes of the students but also make the discipline of engineering a worthwhile field of study.

\section{Literature Review}

Active student engagement has been extensively studied. R.M. Felder defines and Silverman [1] report active learning as 'anything course-related that all students in a class session are called upon to do other than simply watching, listening or taking notes.' Research shows that in student centered teaching, the focus in the classroom must shift from the instructor to the students $[2,3]$. The author has shortlisted a number of active learning techniques that could be applicable to engineering classes. These include Jigsaw puzzles; review of muddiest point; Think-Pair-Share; quiz bowl for studying; use of multi-media; use of props; candy questions; mind breaks; engaged tests; overview, prime, drill, check etc. [3, 4]. In other studies, effective multidisciplinary active learning techniques for freshmen students are explored [5, 6]. It is highlighted how many of these activities applied in non-engineering disciplines are also applicable to engineering courses. The idea of deductive versus inductive learning has been explored extensively in liberal arts. It has been shown that students learn better when they are given the task of student centered active learning in a classroom $[7,8$, and 9]. Malone and Lepper [10] have defined intrinsic motivation in terms of what people will do without external inducement. Active learning techniques applicable to on-line environment have been explored [11,12, 13 and 14].

\section{Research Methodology}

In this study, several professors are asked to respond to the following questions:

1. In your experience, what are some of the techniques one can use to engage students and keep them excited about the class?

2. What are some of the things a professor should not do that could potentially make the classes dull or tedious? 
The professors who participated in this study are all recipient of the prestigious outstanding faculty of the year award at Southern Polytechnic State University. The insight they provide comes from a variety of perspectives. The professors interviewed in this study are from Electrical Engineering Technology, Mathematics, Electrical Engineering, Construction Management, Honors Program, Social and International Studies, and Literature and Composition. Following are advice they give for improving student learning and exciting students about their classes. Some of these come from non-engineering professors but the author believes that the techniques are generic enough to be applicable to engineering courses.

\section{a. Class Projects}

One of the best ways to engage students is through relevant projects. Projects not only re-enforce classroom content, they allow the students to be creative and invest themselves in new ways [15]. Taking written tests alone just doesn't provide a clear picture of student learning. Big multi-week projects could be used but it is observed that even small projects are beneficial.

'This seems strange now but when I started teaching I thought presenting a beautifully written power point lecture was the peak of great teaching' an electrical engineering technology professor reports. Often time professors spend many hours creating content with words of wisdom and high quality pictures. And when they are finished they just assume that their job is over. They assume that the work would speak for itself. All it actually does is put the class to sleep.

After many years of experience, some professors realize that the classroom interaction is what makes class interesting. This includes allowing students to participate in the discussion and feel a part of the discovery and learning. It's a very powerful tool. It's also very helpful to make the learning relevant through grounded examples - examples that the students can relate to in their personal lives. This will get their attention and also make them want to participate in discussions.

\section{b. Teaching the Subject with Interest}

The characteristics of a good professor who makes a class interesting are pretty basic and subtle [16]. 'You want an instructor who knows their subject well, enjoys it, is willing to let their students see their enthusiasm for it, cares about their students, and cares about the education their students receive' a mathematics professor reports. It gets even better if one couples this with a course full of topics and ideas that students are interested in. The professor suggests that 'I think particular techniques are far less important than these two factors, other than the delivery method being one the instructor is comfortable and experienced with and believes is appropriate for the material.'

There are some courses, or topics within courses, that aren't especially fun or interesting for some students, even with the kind of instructor described above. There are elements of every program (and almost any human endeavor, for that matter) that are necessary, but inherently lacking in excitement. And it's also possible for a course to be very popular and exciting, despite a low level of student learning in it. For a variety of reasons, course popularity and student excitement clearly correlate with student learning.

\section{c. Caring for Students}

First and foremost, a professor needs to get students to realize that the professor cares deeply about each and every one of them and wants them to learn and succeed in the course, their other courses, as well as having a balanced approach to the other activities in their lives [17]. A critical way this is shown is by truly knowing their names and other aspects about them. What are they interested in? What motivates them?

After they have a thorough understanding of who is in the class, the professors also need to push them to tremendous lengths. A good professor does not underestimate their capabilities, but requires a substantial amount of participation by all the students through project work or team building exercises which are conducive to the nature of whatever class is being taught. Doing this by example, by not just lecturing but having demonstrations of the material is essential.

'Never ever read to the class. Avoid even using notes too much. Strive to make it as much extemporaneous as possible. Never be too rigid but be willing to flex as needed. Never insult any particular student or tell anyone they are stupid for asking any question' suggests an electrical engineering professor.

\section{d. Making Classes Exciting}

'Mathematics is inherently fascinating' a math professor claims. Enthusiastically, she continues 'Calculus, our bread and butter in the Mathematics Department, is about dealing with the infinite and the infinitesimal in a precise way. What more would anyone need to hear to become excited? This is what people go to university hoping to learn. And calculus is just one sequence of courses. Mathematics is filled with things like this.'

The harsh reality, though, is that calculus, like every field of mathematics and like anything else with any depth, requires its share of "ditch digging," rote learning, learning things that seem designed solely to torture students. Students must memorize some facts. That's not very interesting. Students must learn calculation techniques. These are interesting if one likes that sort of thing but not necessarily if a student wants to understand something about the infinite and the infinitesimal. One must deal with the notion of a limit - a notoriously slippery concept. Students are warned repeatedly for confusing equations with expressions and functions with numbers. In a world where a student thought there is "always a right answer" suddenly they find themselves having to learn and use vocabulary.

The single most important element to make all this compelling is a professor's own expertise and their own appreciation of where the ditch digging will get them. With these, professors can jolly the students along while they struggle to master things they have no interest in, or think they have no interest in [18]. 'I like to remind them over and over of all the mind-blowing aspects of the number line that 
we are revealing to them in calculus' one professor shares. The beauty, the mystery, the joy, staring into the abyss these are pay-offs if one does the ditch digging. By giving the students glimpses of the stars, professors can help keep them engaged. By reminding them over and over that there is "no royal road," but that there is a huge payoff if they take the long route--- not the only route, but one from a choice of long routes - professors can help them understand the larger life lesson that most things take work and that the work itself can be highly gratifying, if one remains engaged and allow what one learns to reveal deeper secrets to themselves.

Several things that are worthy of the struggle to open minds are easy and admirable. On the other hand, if one knows what they are doing in the field - well beyond what they are teaching--- and love the subject, communicate well, care about tweaking their communications so they are effective, listen to students, have the discipline to stay on task, model good habits so that poor organization doesn't get in the way of teaching and learning...then they would become a great role model.

\section{e. Making Connections}

Keeping students engaged requires making a connection between their course/lesson with their career goals. Students need to be aware of their career goals or at least 3-4 possible career goals, if they do not have something specific in mind at the moment. The connection needs to be easily understood by all class participants.

The professor needs to make the connection by first creating awareness about the "content need" for the course/lesson. Then the professor needs to tie the content, with the help of real world examples that students can relate to, with the course learning outcomes [19]. There should be some exams or homework or quizzes that directly measure those learning outcomes to provide feedback to the instructor.

Each lesson plan needs to have a program agenda. If you can show the glimpse of what is next to come than that also enables students to think about it. At the beginning of each lesson if there is a recap of what transpired during the last lesson, that could also help to keep the participant engaged. Every now and then if there is a guest speaker who can break the monotony caused by a single instructor is welcomed by the participants. Quizzing students, one or two times during the class, enables the instructor to keep the focus of the participants. Right answer needs to be rewarded somewhere (GPA or points for class participation etc.). This part could be structured to ensure that everyone in class gets an opportunity to score. Date of return of graded quizzes, exams, home works etc. need to be specified so students know when they can expect to get feedback for their work.

Instructors should never come to the class unprepared. An instructor who comes to the class with textbook power points without making the connection to real life is likely to lose the attention easily. One should never humiliate a student, always encourage them to come prepared and ask "pertinent" questions. The instructor should not change the evaluation criteria for the course midway.

\section{f. Discussions}

To teach a qualitative course well it is important to teach the class in a manner that allows students to see the reading and writing as meaning-making activities in which one tries to understand the world around us. In order to give students a sense of audience for their papers, some professors have in-class discussions. Discussions can also be run on using online course management systems. Professors can run discussion-based classes - sometimes through small groups and sometimes through full class discussions. Peer editing and small-group workshops help students learn how to respond to drafts from other students. Students can learn writing by working through multiple drafts of their papers. Response early on is formative - helping them to see what they could do better to reach their audience - and response at the end is summative - helping them understand how well they did for the final paper. Professors can also meet with composition students for individual writing conferences. Helping students to understand the means by which they will be graded is very important [20]. An honors professor treats students as peers who are using acts of inquiry for communication purposes.

A professor might easily be able to conduct discussion-based classes in certain courses. As a member of the Honors faculty and staff, a literature professor attests to the fact that this pedagogical technique is one that should be encouraged for all Honors faculty, no matter the discipline. When students can actually enter a conversation, ask questions, and share their opinions without fear of a "wrong answer," they naturally are going to be more engaged in a class. 'I ask lots of questions, and I tell them that I expect an answer; I' $m$ interested in hearing what they have to say, and I'm not planning on doing the majority of the talking over the course of the semester' relates the professor. Obviously, there are times when a professor needs to "lecture" in order to help them learn, but one might still work to make it more of a conversation rather than becoming a talking head at the front of the class. When students finally realize that they can speak their own truths rather than what they think the professor wants to hear, they generally become more open. It's not a professor's job to embarrass them into submission. Student opinions need to be valued and they learn a lot from each other when everyone shares in the teaching and learning environment. In order to help those students who are just plain shy when it comes to speaking up in front of 25-35 of their peers, a professor might vary small group discussions and workshops with full-class discussions and workshops. Lastly, participation can be made a certain percent of each student's final grade. A professor might pass a handout on what is expected in terms of participation, and it doesn't mean talking constantly. It might also include listening, respecting the opinions of others, and contributing to a discussion with thoughtful questions, comments, and responses to others.

\section{g. Get them Talking}

One of the active learning techniques is to get the students 
talking, especially to each other. 'I use a lot of small group break-outs with questions to answer or problems to solve; and it's not about the destination, it's about the journey; the process of the discussion is the real point' explains a social science professor. This relates to connecting what goes on in the classroom to the real world. It could be news and current events; better yet, students can be challenged to make the connections. The social science professor requires all her students to identify and comment on additional sources (articles, videos, etc.) each week - and then comment on their classmate's postings. Professors can try to give projects a life beyond the class, a purpose in the real world. It is important to make sure there is enough structure / planning that things don't just drift without direction, but leave room and opportunity for the class to go where the process takes it, to explore unexpected topics or opportunities; let students shape the course, too. Professors can model lifelong learning! keep learning, trying, exploring new things - let the students see that the professors are doing these things, that sometimes they fail, and that it's okay! The social science professor suggests the following to keep the class from becoming dull or boring.

1. Don't do all the "talking" (lecture, film, etc.)

2. Don't control the process too tightly

3. Don't use the same approach in every class

Some professors take role because they are of the opinion that just by being in the class and listening, the student will normally absorb enough information to probably pass the course with a minimum of study and review. Every course can have some form of group project. In most cases, the groups help bring the students together, and each project presentation can be graded by the rest of the class to get them even more involved.

\section{h. Cultural and Historical Context}

Students often respond better when they understand the cultural or historical context of the theory. A history professor uses the approach of "painting" history something like sewing stories together, but with an emphasis on seeing the overall picture and detailing what was happening behind the scenes and the results. In other courses professors can try to center the focus on the basic concepts and wherever possible, apply those concepts to the students' world. An anthropology professor remarks, ' $m y$ focus is not applying core concepts to groups of 200 or 500 people, but developing an understanding of core concepts in relation to the student's own backyard.' Sometimes students can also relate if a geographic reference is explained for in addition to the history.

What a professor should not do is stand there and read power point slides or other text on the screen. It is insulting to the students as they can read the power point themselves. Similarly, they should not cram too much information into a single power point slide. The slides should reinforce what the professor is saying, and not $\mathrm{BE}$ what the professor is saying. In a similar way, a professor should never just stand and read a lengthy passage to the class. Give them copies and let them read it for themselves.

\section{i. Respecting Students}

It is important to respect the students and consider each one individually. While this does not mean surrendering to their total demands, it does mean a willingness to actually listen to the student and respond accordingly. Too many instructors tend to endure a student's recounting of some problem, doubting the substance of what the student is saying. Students need to know that they are important to the professor and being taken seriously by them. In a related vein, the professor should try to be careful not to "put a student down" nor "talk down" to a student.

The main thing a professor shouldn't do is to treat students as though they are less than the professor. Professors should try to treat them with respect no matter what the situation. This is especially important in order to run discussion-based classes well. Not clarifying the grading scheme can be a problem [21]. Syllabi that poorly cover the course are a problem.

A good professor has clear expectations and standards and firmly enforces them. Students may cringe at the expectations, restrictions, or standards, but they will respect the professor if they are consistent and fair about it, even if some requirements seem to be extreme. Professors should neither be fuzzy or unclear in expectations nor wishy-washy. Students will not respect the instructor nor like the course if this is the case. And they will become frustrated themselves over the lack of clarity. In a similar vein, professors should not keep changing the requirements as the course goes along. They might set the requirements and then let it go. After teaching the course once or twice, the students will make very clear what they think is appropriate.

A professor should listen to their students. Ask them for feedback and take seriously what they have to say. A good professor does not assume that everything that is taught and the way it is taught is awesome just because they have done it that way for years. Majority of the students do well in classes of best professor every semester, and that's because they want to. They enjoy what is done in the classroom, and because they are engaged, they are more invested in their grades. If a student does not pass a class or does not do well overall, it's because he/she quits coming to class, misses too many classes, or doesn't hand in work. A student who enjoys a class welcomes the opportunity to experiment with the material and impress his/her professor.

\section{j. Simplicity}

There are so many simple things that a professor might do to keep their students engaged and excited. They can begin each semester with a simple exercise of meeting each and every student and asking the students to meet someone new. This can be done on the first day of classes. Each student finds another student he/she does not already know and introduces himself to the other. Then, all students are responsible for introducing their new "friend" to the entire class. The professor can tell them that this accomplishes a few things:

1. It helps professor to start putting names with faces through personal information about each student; 
2. It helps the students get to know each other and get more comfortable with their classmates; and

3. It forces everyone to speak in front of the class on the first day so they can get over their jitters about speaking in front of others.

By doing this and other similar exercises, the professor learns that many students have a lot in common that they would never know about otherwise. At times they would hear from students who had taken classes together previously but never knew the other person's name because no one spoke but the professor. Plus, students really like that the professor takes the time to learn their names; they are not just "another student." The professor can also share information about themselves (i.e. family, hobbies, volunteer roles in the community, where they are from, etc.)

Another very simple tactic that a professor might use in classrooms is to have the students move their desks into a circle. This really promotes active classroom discussion as opposed to desks lined up in rows with all students only able to see one face...the professor's! Professors get very positive feedback from students on this classroom set-up. A professor might sit in the circle with the students as opposed to in front of the students, and might get up and walk around in the middle of the circle. It makes them more relaxed and open to learn and engage with their peers. This might not be possible in all classrooms, but highly recommended when possible.

\section{k. Providing Feedback}

Another very simple tactic that might be used is to give students positive feedback. A check system might be used for most of the grades in classes (check-plus, check, and check-minus) and this takes a lot of pressure off of the students to get an A or B. They receive the full letter or numerical grades on quizzes, exams, projects and finals. A detailed handout might be given to students at the beginning of each semester that explains the grading system and that it is done that way so that they focus on the soundness of their work rather than the final grade. When it's all about the grade, that's where they put their effort. A professor might be more interested in seeing them develop their critical thinking skills and transferring that to their work. In turn, this makes for stronger grades overall. A professor should give complete responses to their work as well, making suggestions, offering advice, and pointing out errors. It is seen that a simple "Good Job" written on an assignment will give the student the confidence to continue to do his/her best work [22].

For classroom activities, a good professor is constantly looking for new ways to "spice things up". Any good professor might read articles, attend conferences, prepare conference presentations, and attend workshops, etc. in order to better their own teaching effectiveness. One might also ask students for their feedback on a regular basis during the semester, and listen to what they have to say. If a majority of students really do not get much out of a particular assignment, it could be changed for the next semester. If they really do not like a particular reading assignment, a new assignment can be added in lieu of the unfavorable one [23]. A good professor understands what "engages" students on the most basic levels. Even if one thinks one of their assignments is great but the students learn little to nothing and struggle just to get it done, then it's not working, and the professor needs to re-think what they are asking them to do. If they are not learning, then the professor is not doing a very good job of teaching.

\section{Conclusions}

In this paper, a few techniques have been highlighted that professors can use in their engineering classes to promote active learning. It is shocking when one professor mentions to another professor that they "share" a student during the semester, and the other professor has no idea who they are talking about. The first professor ends up having to describe what the student looks like, what he/she acts like, etc. before the other professor says "Oh yes!" This happens more often than not. A professor might teach over 100 students per semester. It is not that hard to get to know one's students and appreciate them as individuals. A good professor avoids being a talking head. It is often seen in engineering classes that the professor is standing in front of a class and is talking, talking, talking. The students are lined up in their rows, and most of them have glazed over looks on their faces. In order to have an engaged class, a professor must engage the students. If a professor believes that their field of expertise does not allow for discussion, then the best faculty members interviewed in this study disagree. In the honors program, mathematics professors have taught discussion-based classes that are very effective for both the professor and the students. It takes some give and take and learning on the part of the professor, but we all can learn how to encourage our students in discussions which leads to much more meaningful learning experiences.

\section{Acknowledgements}

The author would like to acknowledge the following professors at Southern Polytechnic State University for their insight into this important topic: Scott Tippen (Electrical Engineering Technology), Joel Fowler (Mathematics), Lance Crimm (Electrical Engineering), Meg Dillon (Mathematics), Khalid Siddiqi (Construction Management), Nancy Reichart (Honors Program), Julie Newell (Social and International Studies), Richard Bennette (Social and International Studies), Ann Parker (Literature and Composition).

\section{REFERENCES}

[1] Silverman, R.F., 'Learning and Teaching Styles in Engineering Education,' Engineering Education, 78 (7), 674-681. 
[2] Brent, R. F. (2005). Understanding student differences, Journal of Engineering Education, 94(1),57-72

[3] Khalid, A., Nuhfer-Halten, B., 'Enhancing Learning at the Polytechnic University: Interactive Classroom Techniques,' International Journal of Polytechnic Studies, 2012 Vol. 1, No. 2

[4] Brint, S., Cantwell, A., \& Hanneman, R.(2008), 'Two cultures: Undergraduate academic engagement.' Research in Higher Education, 49 (5), 383-402

[5] Khalid, A., Nuhfer-Halten, B., Vandenbussche, J., Colebeck, D., Atiqullah, M., Toson, S., Chin, C., 'Effective multidisciplinary active learning techniques for freshmen polytechnic students,' Review of Higher Education and Self-Learning - RHESL, Vol. 4, Issue 3, December 2011

[6] Carini, R. K.,Kuh, G.,\& Klein, S. (2006). Student engagement and student learning: Testing the linkages. Research in Higher Education , 47 (1), 1-32

[7] Paradowski, M. B., 'Deductive vs. Inductive Teaching [Internet],' Version 3, Knol. 2009

[8] Caufield, J. (2010). Applying graduate student perceptions of task engagement to enhance learning conditions. International Journal for the Scholarship of Teaching and Learning, 4(1)

[9] McKinney, K. (n.d.). What is the Scholarship of Teaching and Learning (SoTL) in higher education? [Retrieved 2011 from

[http://sotl.illinoisstate.edu/downloads/pdf/definesotl.pdf]

[10] Malone, T. W., M. R. Lepper, 'Making Learning Fun: A Taxonomy of Intrinsic Motivation for Learning,' In R.E. Snow and M. J. Farr (Eds.), Aptitude, Learning and Instruction III: Conative and Affective Process Analyses. E Hillsdale N.J., Erlbaum, 1987

[11] Metzger-Linville, I. (2007). Quiz Bowl. Retrieved from [http://4h.missouri.edu/resources/materials/docs/LG732.pdf]

[12] Shank, P. (2005). The value of multi-media in learning. Adobe Design Center. Retrieved from [http://www.adobe.com/fr/designcenter/thinktank/valuemedi a/The_Value_of_Multimedia.pdf]

[13] Shephard, A. (n.d.). Case for computer-based multimedia in adult literacy classrooms. Retrieved 2012, from Encyclopedia of Educational Technology:
[http://www.etc.edu.cn/eet/Articles/adultliteracy/]

[14] Khalid, A. "Improving Engineering student learning through interactive on-line classroom activities," 3rd annual Polytechnic Summit, Southern Polytechnic State University, June 8-10, 2011

[15] Thalheimer, W. (2006, May 16). People remember 10\%, $20 \%$... Oh really? Retrieved from [http://www.willatworklearning.com/2006/05/people_remem ber.html]

[16] Metzler, J., Woessmann, L., 'The Impact of Teacher Subject Knowledge on Student Achievement: Evidence from Within-Teacher Within-Student Variation,' IZA DP. No. 4999, Retrieved on June 16, 2013 from [http://ftp.iza.org/dp4999.pdf]

[17] Teven, J., J., McCroskey, J., C., 'The relationship of perceived teacher caring with student learning and teacher evaluation,' DOI: 10.1080/03634529709379069, Communication Education, Vol. 46, Issue 1, 1997

[18] Teresa, H., Stephen, H., 'Combining an Exciting Classroom Learning Environment with an Effective Computerized Learning Management System,' Journal of Applied Research for Business Instruction, v7 n2 2009

[19] Brian, C., 'The Whole Story: Natural Learning and the Acquisition of Literacy in the Classroom,' Book published by Scholastic, Inc., P.O. Box 7502, Jefferson City, MO 65102 (Item No. 21976)

[20] Almasi, J. F., McKeown, M., G., 'The Nature of Engaged Reading in Classroom Discussions of Literature,' doi: 10.1080/10862969609547913, Journal of Literacy Research March 1996 vol. 28 no. 1 107-146

[21] Ben-Yosef, E., 'Respecting Students' Cultural Literacies,' October 2003, Volume 61, Number 2, Teaching All Students Pages 80-82

[22] Angelo, T., A., Cross, K., P., 'Classroom Assessment Techniques,' Classroom Assessment Techniques: A Handbook for College Teachers, 2nd edition

[23] Boyle, J., Nicol, D., Hamilton, B., Dempster, B., 'Experience with classroom feedback systems to enable socratic dialogue in large engineering classes,' IEE 2nd Annual Symposium on Engineering Education, January 2002 page 16 